\title{
BIO-MEDICAL WASTE MANAGEMENT PRACTICES AMONG HEALTH CARE PROFESSIONALS: A CASE STUDY IN DISTRICT FAISALABAD, PUNJAB PAKISTAN
}

\author{
Nazia Malik \\ Assistant Professor, Department of Sociology Government College University Faisalabad \\ naziamalik@gcuf.edu.pk \\ Zaid Mehmood \\ PhD Scholar, Department of Sociology Government College University Faisalabad \\ zaidrana04@hotmail.com \\ Babak Mahmood \\ Associate Professor, Department of Sociology Government College University Faisalabad \\ babakmahmood@gmail.com
}

\begin{abstract}
Biomedical waste $(B M W)$ is produced during surgical, and medical treatment, vaccination, and diagnostic processes. Owing to its hazardous nature BMW must be carefully segregated, handle and discard. As the healthcare professionals are significant and influential part of any healthcare system so their practices for handling this waste are imperative. Purpose: This study was conducted in public sector hospitals of Faisalabad, Punjab, Pakistan to assess the Bio-medical waste management practices among healthcare professionals. Design/Methodology/Approach: In this cross-sectional quantitative study, 500 respondents was conveniently recruited in which 280 were MBBS doctors and 220 staff nurses serving in different departments of the hospital. A self-designed questionnaire comprises of different statements about practices of healthcare waste management was used for data collection. The collected data was analyzed through SPSS version 24. Findings: The researchers found that although "Hospital Waste Management Rule Pakistan 2005" exists and there are Bio Medical Waste Management (BMWM) committees in the hospitals, the healthcare waste management practices were not up to the mark. Moreover, no proper trainings of the healthcare professionals were conducted.
\end{abstract}

Keywords: Bio Medical Waste Management, Healthcare

\section{INTRODUCTION}

The waste formed in the medical, treatment, surgical treatment, vaccination,' or diagnostic processes is considered as Bio-Medical Waste (BMW) by the World Health Organization. This waste is regarded as different sort of waste, since it is infectious and harmful (Mandal \& Dutta, 2009). Due to its hazardous nature, proper disposal of biomedical waste is crucial however, it has not gotten sufficient consideration in the developing world (Tsakona et al., 2007; Jang et al., 2006; Da Silva et al., 2005; Alagöz \& Kocasoy, 2008). Numerous activities have been made by environment protection offices to deal with the BMW (Prabhu, 2016). These nations need explicit laws and guidelines of biomedical waste administration and others have essential guidelines to oversee biomedical waste but often the developing nations do not follow the WHO standards (Hassan et al., 2012). Pakistan is the fifth most populous country in the world where millions of people visit the public sector hospitals for attaining their medical treatments, and medical investigations each day but the Bio Medical Waste Management (BMWM) in the hospitals doesn't meet the WHO standards (Razzak, et al., 2014). The role of doctors and staff Nurses is vital in the BMWM, so there was a need conduct a study among these healthcare professionals regarding their practices of BMWM in Pakistan.

\section{Objectives}

1. To assess the level of Hospital Waste Management Practices among Health Care Professionals

2. To suggest suitable policy measure to improve the Hospital Waste Management Practices 


\section{REVIEW OF LITERATURE}

Medical clinics produce the harmful and toxic waste worldwide. Handling of this waste have become a significant challenge for the developing nations. Due to the significance of the issue, various researchers in developing nations have examined the BMWM status, practices, and issues in medicinal treatment centers inside their countries and have referenced various explanations behind poor biomedical waste administration practices and status in their distributions (Nemathaga et al., 2008; Marinković et al., 2008; Kumar et al., 2010; Bdour et al., 2007). Proper disposal and treatment of BMW was very essential; however, BMW's handling and management procedures were inadequate and therefore exposed itself and public to health and environmental threats (Shalini, 2010). Clinical waste and its administration were not commonly viewed as an issue till the late 1970s. The US acknowledgment of clinical waste as a different waste inside the city squander in the 1980s and 90's. As per a WHO (World Health Organization) appraisal in 2002 there were almost 22 nations with no legitimate strategies of waste removal which had about 64 percent medical clinics" (Kumar et al., 2010). The worries related to introduction to HIV (human immunodeficiency infection) and hepatitis B infection (HBV) drove studies regarding potential dangers inherent in clinical waste (Arshad et al., 2011). Clinical waste is frequently mixed in with metropolitan strong waste and arranged closed by landfills. Recently numerous endeavors have been made by environment protection departments to deal with the biomedical waste (Prabhu, 2016). In Pakistan, because of various issues such as poor implementation of laws, lack of interest of concerned officers and lack of trainings, the BMWM is a big challenge (Arshad et al., 2011). Currently, various strategies are being utilized to stop the misuse of BMW for example on location burning, steam sanitization, microwave purification, autoclave cleansing, and compound/mechanical sterilization. In Pakistan, like other developing counties, three sorts of techniques are being utilized for removal of the human services squander, for example burning, landfills, and open dumping. However, the proper segregation of waste in the hospitals is very important for the proper management of BMW (Arshad et al., 2011).

\section{THEORETICAL FRAMEWORK}

Theory of planned behavior (TPB) has been used to predict health related behavior of the human, providing strong predictions of behaviors and intentions (Godin \& Kok, 1996, McEachan et al., 2011). It has also been applied for modeling the intensions to improve health related behaviors (Buunk et al., 2011). The researchers hypothesized that TPB can be used for modeling and predicting intentions and behaviors about biomedical waste management practices, considering the assumptions that the healthcare professionals are rational, make systematic use of the information available to them, and consider the implications of their actions before they decide about BMW. Thus, this study used the TPB framework to propose categorized factors that are related to the willingness to seek and undergo proper BMWM practices using the factors influence attitudes, subjective norms, and perceived behavioral control that led to a healthcare professional's intentions and behaviors about BMWM.

\section{TPB components and waste management}

Common aspects of healthcare professional's BMWM-seeking behavior may be identified, considering their potential views, concepts, and attitudes about BMW. We considered that these components may have an influence on an individual's actual behavior, ranging from practices of segregation of BMW to monitoring its proper disposal.

\section{Attitude towards behavior}

An individual's positive or negative attitude towards BMWM practices may be influenced by it perceived consequences due to its infectious and harmful nature. The knowledge of an individual about the hazardous nature of BMW, and its proper handling, transportation and disposal can influence his/her attitude towards BMWM practices.

\section{Subjective Norms}

An individual's perception of social normative pressures, such as the waste management guidelines, training of the staff for BMWM, or recommendations of WHO, and medical associations about the need for special attention towards the prosper disposal of BMW.

\section{Perceived behavior control}


An individual's beliefs about factors that may facilitate or make difficult to seek proper treatment of BMW may include factors related to the availability of proper wastebins, workload of the staff, and role of hospital's BMWM committee.

\section{METHODOLOGY}

This quantitative study was conducted among the health care professionals to assess the bio-medical waste management practices in the public sector hospitals of Faisalabad Punjab Pakistan. The medical officers (Doctors) and staff nurses were the target population that were recruited through multistage sampling. At the first step, two public sector hospitals District Head Quarter Hospital Faisalabad, and Allied Hospital Faisalabad were randomly selected from all public sector hospitals in Faisalabad. Afterward using convenient sampling method, 500 respondents from both selected hospitals were interviewed in which 250 respondents from each hospital were recruited to collect data. The following inclusion criteria was followed by the researchers: -

1. The respondent must be a permanent employee of the Hospital

2. Working for more than one year in the hospital under study

The staff not willing to participate in the study were excluded. Also, the staff working on contract basis were not included in this study. The purpose of the study was clearly stated to the respondents and informed consent was also taken before data collection. A self-designed interview schedule was structured in accordance with the previous literature about bio-medical waste management practices and guidelines of Hospital Waste Management Rule Pakistan 2005. The collected data was analyzed through Statistical Package for Social Sciences (SPSS version 24).

\section{MAJOR FINDINGS}

Table No. 1 Profile of the Respondents

\begin{tabular}{|c|c|c|c|}
\hline Sr. No & \multicolumn{3}{|c|}{ Characteristics of the respondents } \\
\hline \multirow[t]{3}{*}{1} & The respondents' genders & $f$ & $\%$ \\
\hline & Male & 225 & 45.0 \\
\hline & Female & 275 & 55.0 \\
\hline \multirow[t]{4}{*}{2} & Ages of the respondents & $f$ & $\%$ \\
\hline & 20 to 25 & 231 & 46.2 \\
\hline & 26 to 30 & 210 & 42.0 \\
\hline & 31 above & 59 & 11.8 \\
\hline \multirow[t]{3}{*}{3} & Job categories & $f$ & $\%$ \\
\hline & Doctors & 280 & 56.0 \\
\hline & Staff Nurses & 220 & 44.0 \\
\hline \multirow[t]{6}{*}{4} & Working departments & $f$ & $\%$ \\
\hline & OPD & 72 & 14.4 \\
\hline & Surgical Ward & 317 & 63.4 \\
\hline & Emergency & 39 & 7.8 \\
\hline & Medical Ward & 69 & 13.8 \\
\hline & Others & 3 & .6 \\
\hline \multirow[t]{3}{*}{5} & Work experience & $f$ & $\%$ \\
\hline & Up to 3 years & 230 & 46.0 \\
\hline & 4 years to 6 years & 241 & 48.2 \\
\hline
\end{tabular}




\begin{tabular}{|c|c|c|c|}
\hline & Above 6 years & 29 & 5.8 \\
\hline
\end{tabular}

Table no 1 shows that 45.0 percent respondents were male although 55.0 percent respondents were female. As all the staff nurses were female, and many doctors were also female therefore the percentage of female respondents is higher than that of the male. Regarding age group the data showed that 46.2 percent respondents consisted of age category 20 to 25 . While 42.0 percent respondents consisted of age group 26 to 30 and only 11.8 percent respondents consisted of age category 31 above. The study was conducted among the two segments of healthcare professionals. The data reflect that 56.0 percent respondents were doctors, whereas 44.0 percent respondents were Staff Nurses. The researchers recruited respondents from variety of departments to make the study more comprehensive. So, the above table illustrate that 14.4 percent respondents were performing their duties in OPD department, 63.4 percent in surgical ward, 7.8 percent respondents in emergency 13.8 percent respondents in medical wards, and only 0.6 percent respondents were performing their duties in other departments. The healthcare professionals working for more than one year in the hospital were included in the sample of this study, so data shows that 46.0 percent of the respondents had working experience of working between 1 year to 3 years, working experience of 48.2 percent respondents was 4 years to 6 years, experience of 5.8 percent was above 6 years.

\section{Table No. 2}

\begin{tabular}{|c|c|c|c|c|c|c|c|c|c|}
\hline \multirow[t]{2}{*}{$\begin{array}{l}\text { Sr. } \\
\text { No }\end{array}$} & \multirow[t]{2}{*}{ Statement } & \multicolumn{2}{|c|}{$\begin{array}{l}\text { To a } \\
\text { greater } \\
\text { extent }\end{array}$} & \multicolumn{2}{|c|}{$\begin{array}{l}\text { To some } \\
\text { extent }\end{array}$} & \multicolumn{2}{|c|}{ Not at all } & \multicolumn{2}{|c|}{ Total } \\
\hline & & $f$ & $\%$ & $f$ & $\%$ & $f$ & $\%$ & $f$ & $\%$ \\
\hline 1 & $\begin{array}{l}\text { To what extent you follow the practice of } \\
\text { segregation of BMW during the duty } \\
\text { hours? }\end{array}$ & 386 & 77.2 & 114 & 22.8 & 0 & 0 & 500 & 100 \\
\hline 2 & $\begin{array}{l}\text { To what extent you force the junior staff, } \\
\text { patients, and their attendants to use } \\
\text { proper (colour-coded) wastebins? }\end{array}$ & 366 & 73.2 & 70 & 14.0 & 64 & 12.8 & 500 & 100 \\
\hline 3 & $\begin{array}{l}\text { Do you think that the waste management } \\
\text { guideline is mentioned near the } \\
\text { wastebins and waste area throughout the } \\
\text { hospital? }\end{array}$ & 284 & 56.8 & 204 & 40.8 & 12 & 2.4 & 500 & 100 \\
\hline 4 & $\begin{array}{l}\text { BMWM committee of the hospital is } \\
\text { properly functional? }\end{array}$ & 242 & 48.4 & 130 & 26.0 & 128 & 25.6 & 500 & 100 \\
\hline 5 & $\begin{array}{l}\text { The management of hospital conduct } \\
\text { proper training of the staff for BMWM? }\end{array}$ & 163 & 32.6 & 327 & 65.4 & 10 & 2.0 & 500 & 100 \\
\hline 6 & $\begin{array}{l}\text { Are disposal of waste practice in the } \\
\text { hospital according to "Hospital Waste } \\
\text { Management Rule Pakistan 2005"? }\end{array}$ & 115 & 23.0 & 169 & 33.8 & 216 & 43.2 & 500 & 100 \\
\hline
\end{tabular}

The handling, transportation and disposal of BMW depends upon the segregation of different types of waste. Table No. 2 shows that majority of the respondent's (77.2\%) to a greater extent follow the practice of segregation of BMW during the duty hours and only 22.8 percent of the respondents claimed that they "to some extent" follow the practice of segregation of BMW during their duty hours. $73.2 \%$ respondents were of the view that they were "to a greater extent" and 14.0 responded that they "to some extent" were convincing the people around them to use proper (color-coded) wastebins. However, 12.8 respondents asserted that they "not at all" force their subordinates, the patients, and their attendants for the use of proper (color-coded) wastebins. Majority of the respondents (56.8 percent) were "to a greater extent" agreed that Waste management guideline are mentioned near the wastebins and waste area. While 40.8 percent respondents were "to some extent" agreed with the same. It reflects that waste management guideline were missing at many places. 2.4 percent respondents however answered that the waste management guidelines were not mentioned near the wastebins and waste area throughout the hospital. These guidelines help to encourage the respondents to follow the BMWM rules. Proper functioning of BMWM committee of any hospital is 
important to ensure the safe handling and proper disposal of BMW however from the segment under study, 48.4 percent respondents were to a greater extent agreed that BMWM committee of the hospital was properly functional whereas 26.0 percent respondents were "to some extent" agreed with the same. However, 25.6percent respondents were of the view that BMWM committee of the hospital was "not at all" functional. The on-job trainings, seminars and workshops are a major source of spreading awareness about a particular issue among the staff of any organization. The trainings of staff can help to spread awareness and sense of responsibility regarding use of appropriate wastebins. The data in this regard implies that 32.6 percent respondents "to a greater extent" and 65.4 percent respondents "to some extent" were agreed that management of hospital conduct proper training of the staff for BMWM. Two percent respondents were of the view that management of hospital was not conducting proper training of the staff for BMWM. Regarding the implementation of the "Hospital Waste Management Rule Pakistan 2005", 23.0 percent respondents replied that the said rule was "to a greater extent" and 33.8 percent respondents said that it was "to some extent" implemented in the hospital. A significant number 43.2 percent respondents were of the view that the rule was "not at all" implemented in the hospital. It reflects the poor performance of the BMWM committee of the hospitals.

\section{DISCUSSION AND CONCLUSION}

Current study was conducted among the healthcare professionals to assess the bio-medical waste management practices in the public sector hospitals of Faisalabad, Punjab, Pakistan. All the respondents recruited in this study were the permanent employees of the hospital working for at least more than one year in the hospital. The respondents were recruited from different departments to collect a more reliable and comprehensive data. Segregation of waste at source is important for the proper handling, transportation, and disposal of the waste. The wastebins of various colors are used in the hospitals for this purpose. However, the responses reflect that practice of segregation of BMW were not strictly carried out. Like research by Bdour et al., (2007) which discovered "bad waste classification and segregation procedures in hospitals and medical laboratories." Although the Doctors, and Staff Nurses knew the color codes used for segregation of different types of waste and they were emphasizing to use those waste bins accordingly. However, the junior staff, clerical staff of the hospitals, and especially the patients, and their attendants were not aware of the use of the proper wastebins. Even where the instructions for the use of these wastebins were mentioned, many staff members, patients and their attendants were not using proper wastebins. It reflects careless attitude of the hospital staff. Like previous research by Hassan et al., (2012) which revealed that the Management of most hospitals in Pakistan showed a careless collection, transportation, and disposal of BMW. The role of BMWM committee of the any hospital is significant in the whole process of segregation, handling, transporting and disposal of the waste. Also, this committee is responsible to train the hospital staff that how to deal with this hazardous waste. The findings however reflect the poor attention of the BMWM committees of the hospitals. Kumar et al., (2010) also mentioned that during the past decade, studies show various explanations behind the poor BMWM practices in Pakistan for instance, lack of attention by healthcare professionals, absence of interest of staff, absence of guidelines and training mechanisms, and absence of funds.

Data in this study also showed that management of hospitals was conducting trainings of the staff for BMWM, but these trainings were not up to the mark. It reflects that there is need to conduct proper trainings of the staff in this connection. Like a previous study by Hassan et al., (2012) that was carried out in eighteen separate hospitals of Khyber Pakhtunkhwa, Punjab, and Islamabad. The authors narrated that many private and public hospitals in Pakistan do not conduct proper training of BMWM as specified by the Government. The research also highlighted

For the proper disposal of hospital waste and proper BMWM, the Federal Government of Pakistan made Hospital Waste Management Rule Pakistan 2005, based on environment protection act 1997. These rules are implemented in all the public sector and private hospitals for environmental protection. But the data reflects the poor implementation of the Hospital Waste Management Rule Pakistan 2005. The results show the lack of sense of responsibility among the hospital staff, and poor monitoring of the concerned departments. These finding are like a previous study by Sharma \& Chauhan, (2008) in India who mentioned that major problems behind the poor BMWM are the lack of responsibilities, wrong practices of BMWM among the healthcare professionals, and less 
accountabilities for the misuse and mishandling of BMW. When the waste is not disposed properly, it causes some serious complications for the environment and people who breathe near it. The mishandling of this waste contaminate the soil and water and it can also lead to an epidemic disease.

\section{RECOMENDATIONS}

1. The need for effective training program of BMWM that target every staff member of the hospitals

2. Continuous monitoring and supervision mechanisms must be developed for effective implementation of the SOPs of biomedical waste management in hospitals.

\section{REFERENCES}

Alagöz, A. Z., \& Kocasoy, G. (2008). Determination of the best appropriate management methods for the health-care wastes in Istanbul. Waste Management, 28(7), 1227-1235.

Arshad, N., Nayyar, S., Amin, F., \& Mahmood, K. T. (2011). Hospital waste disposal: a review article. Journal of Pharmaceutical Sciences and Research, 3(8), 1412.

Bdour, A., Altrabsheh, B., Hadadin, N., \& Al-Shareif, M. (2007). Assessment of medical wastes management practice: a case study of the northern part of Jordan. Waste management, 27(6), 746-759.

Buunk-Werkhoven, Y. A., Dijkstra, A., \& van der Schans, C. P. (2011). Determinants of oral hygiene behavior: a study based on the theory of planned behavior. Community Dent Oral Epidemiol, 39(3):250-259.

Da Silva, C. E., Hoppe, A. E., Ravanello, M. M., \& Mello, N. (2005). Medical wastes management in the south of Brazil. Waste Management, 25, $600-605$.

Godin, G., \& Kok, G. (1996). The theory of planned behavior: a review of its applications to healthrelated behaviors. Am J Health Promot. 11(2): 87-98.

Hassan, A. A., Tudor, T., \& Vaccari, M. (2018). Healthcare waste management: A case study from Sudan. Environments, 5(8), 89.

Hassan, A. O., Hassan, R. O., Muhibi, M. A., \& Adebimpe, W. O. (2012). A survey of Enterobacteriaceae in hospital and community acquired infections among adults in a tertiary health institution in Southwestern Nigeria. African Journal of Microbiology Research, 6(24), $5162-5167$.

Jang, Y. C., Lee, C., Yoon, O. S., \& Kim, H. (2006). Medical waste management in Korea. Journal of environmental management, 80(2), 107-115.

Kalpana, V. N., Prabhu, D. S., Vinodhini, S., \& Devirajeswari, V. (2016). Biomedical waste and its management. Journal of Chemical and Pharmaceutical Research, 8(4), 670-676.

Kumar, R., Khan, E. A., Ahmed, J., Khan, Z., Magan, M., Nousheen, N., \& Mughal, M. I. (2010). Healthcare waste management (HCWM) in Pakistan: current situation and training options. Journal of Ayub Medical College Abbottabad, 22(4), 101-106.

Mandal, S. K., \& Dutta, J. (2009). Integrated bio-medical waste management plan for Patna city. Institute of Town Planners.

Marinković, N., Vitale, K., Afrić, I., \& Janev Holcer, N. (2005). Hazardous medical waste management as a public health issue. Arhiv za higijenu rada i toksikologiju, 56(1), 21-32.

McEachan, R., Conner, M., Taylor, N. J., \& Lawton, R. J. (2011). Prospective prediction of healthrelated behaviours with the Theory of Planned Behaviour: a meta-analysis. Health Psychol Rev, 5(2):97-144.

Nemathaga, F., Maringa, S., \& Chimuka, L. (2008). Hospital solid waste management practices in Limpopo Province, South Africa: A case study of two hospitals. Waste management, 28(7), 1236-1245.

Razzak, N. R. B., Chowdhury, S., \& Chowdhury, F. (2014). A study on health care waste management in some selected hospitals of Dhaka city. Journal of applied science and research, 2(1): $161-168$. 
Shalini, S. (2010). Awareness about bio-medical waste management among health care personnel of some important medical centers in Agra. International Journal of Environmental Science and Development, 1(3), 251-255.

Sharma, S., \& Chauhan, S. V. S. (2008). Assessment of bio-medical waste management in three apex Government hospitals of Agra. Journal of Environmental Biology, 29(2), 159.

Tsakona, M., Anagnostopoulou, E., \& Gidarakos, E. (2007). Hospital waste management and toxicity evaluation: a case study. Waste management, 27(7), 912-920. 